\title{
EDUCAÇÃO FÍSICA E TEORIA DAS CINCO PELES: UMA REVISÃO SISTEMÁTICA
}

\author{
PHYSICAL EDUCATION AND THE FIVE SKINS THEORY: A SYSTEMATIC \\ REVIEW
}

\author{
EDUCACIÓN FISICA Y TEORIA DE LAS CINCO PIELES: UNA REVISIÓN \\ SISTEMÁTICA
}

\author{
Dênis Oliveira Decussatti ${ }^{\star}$, Fábio Luís Santos Teixeira**, \\ Iraquitan Oliveira Caminha **
}

Palavras-chave

Teoria das

Cinco Peles.

Hundertwasser.

Educação Física.

Keywords

Five-skin theory.

Hundertwasser.

Physical Education.

Palabras clave

Teoría de las

cinco pieles.

Hundertwasser.

Educación Física.
Resumo: O objetivo deste estudo é compreender de que forma a Teoria das Cinco Peles é abordada na Educação Física. Realizamos uma busca de artigos em bases de dados utilizando descritores específicos. Registramos cinco estudos que põem em diálogo a Teoria das Cinco Peles e a Educação Física, admitindo elementos extracorpóreos como pertencentes ao próprio corpo. Os estudos associam os elementos extracorpóreos a relações de corresponsabilidade, vinculando a implicações sobre o meio ambiente. Conclui-se que há uma predominância em refletir sobre a quinta pele da teoria de Hundertwasser.

Abstract: This study aims at understanding how the five skins theory is addressed in Physical Education. We conducted a database search for articles using specific descriptors. We found five studies where that theory dialogues with Physical Education, admitting extracorporeal elements as belonging to the body. Those studies associate extracorporeal elements to relations of co-responsibility, linking them to environment aspects. It concludes that reflecting on Hundertwasser theory's fifth skin prevails.

Resumen: El objetivo de este estudio es comprender cómo se aborda la Teoría de las Cinco Pieles en la Educación Física. Hemos llevado a cabo una búsqueda de artículos en bases de datos utilizando descriptores específicos. Se registraron cinco estudios que muestran el diálogo entre la Teoría de las Cinco Pieles y la Educación Física, admitiendo elementos extracorporales como pertenecientes al propio cuerpo. Los estudios asocian elementos extracorporales a las relaciones de la responsabilidad compartida, vinculando las implicaciones sobre el medio ambiente. Llegamos a la conclusión de que predomina la reflexión sobre la quinta piel de la teoría Hundertwasser.
${ }^{*}$ Faculdade Maurício de Nassau. João Pessoa, PB, Brasil.

E-mail: decussatti@gmail.com

** Universidade Federal da Paraíba (UFPB). João Pessoa, PB, Brasil. E-mail: fabioesef@ hotmail.com

Recebido em: 09-05-2015 Aprovado em: 07-10-2015 (c) (1) (8) Licence 


\section{INTRODUÇÃO}

A Áustria de 1928 concebeu ao mundo um artista capaz de refletir sobre corpo humano a partir dos espaços que ocupa, rompendo em suas obras com a linearidade e racionalidade da arte. Hundertwasser, pintor e arquiteto naturista, traz uma nova possibilidade da relação do ser humano com seu corpo, espaços e tempos que o conectam com o mundo (OLIVEIRA, 2012). Nas elaborações iniciais de suas obras a linha reta é mãe de todos os males, pois constrói a uniformidade e a rigidez que, por sua vez, não representam o corpo humano (HUNDERTWASSER, 1964).

Sua reflexão sobre a linha reta torna-se evidente na fase da pintura do artista. Hundertwasser (1975) adota o espiral como elemento central de suas telas, uma vez que, na perspectiva do artista, o espiral é 0 antídoto à hegemonia da linha reta, ao mesmo tempo em que é um elemento essencial para a reflexão criativa do ser humano. Em sua teoria, o espiral representa a introversão da vida. As linhas convergidas para o centro indicam a reflexão que 0 homem direciona aos elementos essenciais de sua vida, nesse caso, seu próprio corpo.

0 desgosto pela linha reta e a reflexão sobre o corpo humano também são características marcantes em sua fase da arquitetura. Na elaboração dos projetos arquitetônicos, Hundertwasser (1964) se referia às edificações como o habitat do corpo, constituídas por cores e formas, capazes de revelar características da personalidade do

seu habitante. Sendo assim, se a casa carrega consigo informações do seu morador, ela pode ser compreendida como uma extensão do seu próprio corpo.

Motivado por reflexões próprias das fases da pintura e arquitetura, Hundertwasser, em seus traços e relatos, concebe a teoria sobre a existência de um corpo plural, assimétrico, que se permite compor pelos matizes de suas alteridades (PERETTA, 2007). Em sua concepção, o corpo humano é composto por dimensões exteriores ao próprio organismo, desenrolando-se rumo ao infinito.

Nesse contexto, surge a Teoria das Cinco Peles, definida por Peretta (2007) como representante de um corpo com fronteiras porosas e fluidas, dilatado e ampliado, composto por instâncias plurais, inclusive por esferas extra-humanas, capaz de potencializar em si mesmo uma discussão sobre ética, sentimento e corresponsabilidade para com o outro. Vale salientar que a obra deixada por Hundertwasser consiste em pinturas, manifestos, construções arquitetônicas e roupas confeccionadas, e por esse motivo a produção científica a que temos acesso é resultado de pesquisas ligadas a sua obra. Mesmo assim, não descartamos a necessidade de enfatizar a liberdade que a teoria nos traz de construir nosso próprio corpo, por meio das palavras do próprio artista que, por sua vez, em seus discursos, utilizava elementos $\mathrm{da}$ arquitetura para pensar o corpo humano: "All occupants must be free to create their "outer skins" - they must be free to determine and transform the outward shell of their domicile facing the street" (HUNDERTWASSER, 1964, p. 1).

As múltiplas peles criadas por Hundertwasser posicionam o homem no mundo atual, subdividindo suas relações com o corpo e o mundo em cinco diferentes camadas. A primeira pele é constituída pela epiderme, capaz de registrar a história do homem com suas rugas e expressões corporais. A segunda pele é o vestuário, visto que revelamos nossa personalidade 
por meio das roupas que vestimos. A terceira pele, por sua vez, é a casa do ser humano, denunciando nossa organização e preferências pessoais. A quarta pele consiste no meio social em que vivemos, expondo nossa cultura, crenças e percepções da vida de acordo com as relações que construímos. Por fim, a quinta pele é o planeta, englobando todas as peles citadas, garantindo a sobrevivência humana (OLIVEIRA, 2012).

No nosso entendimento, a Teoria das Cinco Peles aponta para uma compreensão do corpo do ponto de vista existencial. Chegamos, com Merleau-Ponty (1992), a esse entendimento com base na noção de corpo enquanto carne. Do mesmo modo que Hundertwasser representa suas reflexões existenciais por meio das peles, Merleau-Ponty propõe a noção carne.

Pele e carne são instâncias de relação. Segundo as teorias, ambas são superfícies de comunicação inseparáveis. Quando chegamos ao limite da nossa pele ou carne, entramos em contato com as do próximo, estabelecendo, assim, uma relação de comunicação contínua.

Hundertwasser (1990) escreve sobre essa comunicação contínua em seu manifesto Window Dictatorship and Window Right. Para o artista, quando se pensa em casas, há uma tendência de se ressaltar as paredes, desconsiderando as janelas como canais de comunicação. As janelas servem para revelar o sentido de pele que Hundertwasser, por exemplo, atribui à casa na medida em que elas são meios de contato com outras peles.

Embora a teoria aponte para uma compreensão do corpo do ponto de vista existencial, na qual encontramos profundas reflexões relacionadas a corpo humano, e, por esse motivo, possua uma relação aproximada com a Educação Física, poucos são os estudos que buscam essa aproximação. Para Peretta (2007), essa aproximação pode auxiliar a área da Educação Física a ressignificar a hegemonia do padrão fisiológico do corpo humano. Diante da escassez de estudos combinada à incitação de Peretta (2007), o presente artigo questiona: quais os estudos aproximam a Teoria das Cinco Peles da Educação Física?

Investigar quais estudos aproximam a tais teorias é, portanto, o objetivo dessa revisão. Mais especificamente, almejamos apontar as discussões teóricas que relacionam a teoria à Educação Física, bem como sugerir uma compreensão da Educação Física com base na Teoria das Cinco Peles a partir dos estudos analisados.

\section{METODOLOGIA}

O presente estudo consiste em uma revisão sistemática, compreendida por Gomes e Caminha (2014) como método útil para ciências do movimento humano, oferecendo capacidade de síntese e novos direcionamentos. Especialmente para área da saúde, em razão da sua necessidade de atualização do conhecimento, as revisões sistemáticas são cada vez mais valorizadas pela comunidade científica (BENTO, 2014). Nessa mesma perspectiva, Schutz, Sant'ana e Santos (2011) definem a revisão sistemática como método baseado em critérios predeterminados e evidências científicas consistentes, tendo como fim colaborar com a escolha de estudos para o desenvolvimento de artigos com informações originais. 
Nesse contexto, a presente revisão sistemática realizou um levantamento sobre estudos que correlacionassem a Teoria das Cinco Peles à Educação Física. Esta pesquisa foi realizada nas bases de dados Portal de Periódicos da Capes, ScIELO e LILACS. Os descritores utilizados para a averiguação de artigos pertinentes a essa revisão foram: Teoria das Cinco Peles, Hundertwasser e Educação Física.

A pesquisa revelou ausência de artigos ligados à temática referida. Diante desse quadro, optamos por realizar pesquisas em revistas da área que tradicionalmente tratam de questões teóricas considerando seus escopos, bem como no Google Acadêmico, com possibilidade de se encontrar dissertações e teses sobre 0 assunto. Em relação às revistas selecionadas para realizar a pesquisa, procedemos em duas fases. Na primeira, buscamos revistas que possuem Qualis A1, A2, B1 e B2 para a área de conhecimento Educação Física, seguindo a classificação atual de periódicos científicos Sistema Webqualis. Em seguida, realizamos uma seleção a partir dos títulos dos periódicos, seguida de uma análise do escopo das revistas de maneira a identificar aquelas que abrangeriam os temas: Educação Física, arte, educação e corpo. Depois da identificação final das revistas, buscamos artigos referentes a Hundertwasser e à Teoria das Cinco Peles, utilizando as ferramentas de busca das próprias revistas. Artigos correspondentes à proposta de estudo foram identificados apenas na Revista Brasileira de Ciências do Esporte (RBCE).

Em relação à pesquisa realizada no Google Acadêmico, esta revelou quatro estudos pertinentes à proposta da revisão. Mais especificamente, dois artigos científicos e duas dissertações. Os estudos foram localizados em: Revista Espaço Acadêmico, Atos de Pesquisa em Educação e Biblioteca Virtual da Universidade Federal de Santa Catarina (UFSC).

Vale lembrar que os estudos foram selecionados a partir dos seguintes critérios de inclusão: disponibilidade do texto completo; publicação no período compreendido entre os anos de 2000 e 2015 (optamos por esse período em razão do falecimento de Hundertwasser em 2000, o que mobilizou uma ampla divulgação de seu trabalho); idioma português, inglês ou espanhol; vínculo entre a Teoria das Cinco Peles e Educação Física. Neste caso, foram excluídos apenas artigos que não aproximavam a discussão da Teoria das Cinco Peles à área de Educação Física e por isso não se mostravam compatíveis com a proposta dessa revisão.

Para a análise de dados foi utilizada a técnica de análise de discurso, que, por sua vez, visa refletir sobre as condições de produção e compreensão dos significados dos textos, buscando perceber o modo de funcionamento, os princípios de organização e as formas de produção social do sentido (MINAYO, 2000).

\section{RESULTADOS E DISCUSSÃO}

Os cinco estudos selecionados encontram-se expostos no quadro a seguir (quadro 1). Destacamos os autores, filiação dos autores, título dos estudos, ano de publicação, objetivos de cada investigação, além da relação existente entre a Teoria das Cinco Peles e Educação Física. 
Quadro 1 - Estudos que relacionam a Teoria das Cinco Peles e Educação Física

\begin{tabular}{|c|c|c|c|}
\hline Referência & Título & Objetivo & $\begin{array}{c}\text { Relação: Teoria das } \\
\text { Cinco Peles e Educação Física }\end{array}$ \\
\hline $\begin{array}{l}\text { Peretta, } \\
2005^{\star}\end{array}$ & $\begin{array}{c}\text { Alteridades da } \\
\text { pele, fronteiras do } \\
\text { corpo }\end{array}$ & $\begin{array}{l}\text { Construir outra concepção de } \\
\text { corpo humano, inspirado pela } \\
\text { arte e dimensão estética. }\end{array}$ & $\begin{array}{l}\text { Concepção de corpo que não } \\
\text { prima pela eficácia, potência, força, } \\
\text { performance ou velocidade, mas } \\
\text { constituído por dimensões daquilo que } \\
\text { lhe é estrangeiro. }\end{array}$ \\
\hline $\begin{array}{l}\text { Peretta, } \\
2007^{\star *}\end{array}$ & Anatomia altruísta & $\begin{array}{l}\text { Ressignificar a hegemonia do } \\
\text { padrão fisiológico e narcíseo } \\
\text { de corpo humano. }\end{array}$ & $\begin{array}{l}\text { Implosão da concepção de indivíduo } \\
\text { narcíseo e autista constituído pela } \\
\text { modernidade. Despertar para a } \\
\text { concepção de corpo representado por } \\
\text { uma anatomia altruísta, sugerindo a } \\
\text { possibilidade de ser fora do ser. }\end{array}$ \\
\hline $\begin{array}{l}\text { Silva, } \\
2007^{\star}\end{array}$ & $\begin{array}{l}\text { Corpo e natureza: } \\
\text { perspectivas para } \\
\text { uma educação do } \\
\text { corpomundo }\end{array}$ & $\begin{array}{l}\text { Analisar e construir princípios } \\
\text { teórico-metodológicos na } \\
\text { Educação Física, numa } \\
\text { perspectiva onde a educação } \\
\text { corporal não se apresente } \\
\text { descolada de preocupações } \\
\text { éticas, estéticas e ecológicas. }\end{array}$ & $\begin{array}{l}\text { Refletir sobre as relações do corpo } \\
\text { humano com o mundo no processo } \\
\text { de sensibilização e construção de sua } \\
\text { consciência e expressividades através } \\
\text { da concepção de corpo sugerida pelo } \\
\text { pintor Friedensreich Hundertwasser. }\end{array}$ \\
\hline $\begin{array}{c}\text { Dias; Abrão, } \\
2010^{* *}\end{array}$ & $\begin{array}{c}\text { Projeto cinco } \\
\text { peles: educação } \\
\text { para o consumo } \\
{[\ldots]}\end{array}$ & $\begin{array}{l}\text { Questionar os hábitos de } \\
\text { consumo, tendo como base a } \\
\text { Teoria das Cinco Peles. }\end{array}$ & $\begin{array}{l}\text { A reflexão sobre consumo e cooperação } \\
\text { abordada na Teoria das Cinco Peles } \\
\text { foi fomentada por meio de atividades } \\
\text { corporais práticas, ligadas à ludicidade. }\end{array}$ \\
\hline $\begin{array}{l}\text { Oliveira, } \\
2012^{\star *}\end{array}$ & $\begin{array}{l}\text { Hundertwasser } \\
\text { corpo imenso } \\
\text { educador }\end{array}$ & $\begin{array}{l}\text { Investigar a influência } \\
\text { do pensamento de } \\
\text { Hundertwasser no campo } \\
\text { da educação e do corpo na } \\
\text { contemporaneidade. }\end{array}$ & $\begin{array}{l}\text { Pensar em uma educação ligada } \\
\text { a sensibilidade e criatividade, } \\
\text { fomentando um transbordamento das } \\
\text { práticas escolares não mais em eixos } \\
\text { disciplinares, mas em redes e saberes } \\
\text { orientados a uma nova prática social. }\end{array}$ \\
\hline
\end{tabular}

No intuito de organizar nossa análise, optamos por, inicialmente, realizar uma breve descrição de como cada estudo aproxima a Teoria das Cinco Peles à área da Educação Física. Após essa descrição, buscamos apontar as concepções dos autores sobre a Teoria das Cinco Peles no contexto da Educação Física. Por fim, na fase conclusiva desse artigo, revelamos uma compreensão da Educação Física com base na Teoria das Cinco Peles a partir dos estudos analisados.

\subsection{Cinco Peles e Educação Física: as concepções dos autores}

A obra Alteridades da Pele, Fronteiras do Corpo consiste em uma dissertação apresentada ao programa de pós-graduação em Educação Física da Universidade Federal de Santa Catarina (UFSC). Peretta (2005) constrói seu texto em forma de ensaio pois, para 0 
autor, essa é a forma de escrita ligada à liberdade, não desejando deparar-se com a construção fechada, dedutiva ou indutiva, representando a verdade totalizante. Na visão do autor, o ensaio é uma forma de escrita inacabada, e, por isso, utilizá-la demonstra uma atitude coerente ao objeto de estudo, no caso, a Teoria das Cinco Peles.

A incompletude é uma das principais características da obra de Hundertwasser. Essa peculiaridade do artista não influenciou apenas a forma como Peretta (2005) escreveu sua dissertação, mas também a legitimação de suas ideias. Em seu texto, o autor reafirma a construção de uma nova concepção de corpo humano, inspirado pela arte e dimensão estética e, por isso, eternamente inacabado.

O corpo humano proposto por Hundertwasser e reafirmado pelo autor seria inacabado porque admite dimensões daquilo que lhe é estrangeiro. Esse corpo não prima pela eficácia, potência, força, performance ou velocidade, mas, sim, pela história inscrita em nossa própria pele.

As reflexões de Peretta (2005) sobre o significado de corpo humano reforçam-se no artigo, proveniente de sua dissertação, intitulado Anatomia Altruísta. Nesse estudo, o objetivo é ressignificar a hegemonia do padrão fisiológico e narcíseo de corpo humano. Para o autor, atualmente há uma evidência do corpo esbelto, produtivo, competitivo, que busca livrar-se das marcas da sua história, da flacidez e do envelhecimento. Entretanto, é importante destacar a perspectiva que concebe o ser humano não a partir de sua individualidade, mas, sim, composto pelas tensões e contradições inerentes às relações do mundo com o próprio corpo.

Sendo assim, nesse artigo, Peretta (2007) defende a implosão da concepção de indivíduo narcíseo e autista constituído pela individualidade, despertando para a concepção de corpo representado por uma anatomia altruísta, sugerindo a possibilidade de ser fora do ser. Nas análises do autor fica clara a valorização das esferas extra-humanas, potencializando discussões sobre ética, sentimento e corresponsabilidade com o outro.

Podemos perceber na dissertação produzida por Peretta (2005), assim como no artigo resultante das suas reflexões, a utilização dos significados dados ao corpo humano para se pensar questões que extrapolem a dimensão corporal. À primeira vista, a discussão dos dois estudos é sobre significados dados ao corpo, mas uma leitura mais atenta revela reflexões sobre ética, sentimentos e corresponsabilidade. Essa é uma tendência da Educação Física, utilizar conceitos próprios da área para refletir sobre aspectos que superem o corpo orgânico, anatômico e fisiológico.

Outro estudo que aproxima a Teoria das Cinco Peles da Educação Física é a dissertação, igualmente ligada à Universidade de Santa Catarina (UFSC), intitulada Corpo e Natureza: Perspectivas para uma Educação de Corpomundo. Silva (2007) constrói essa dissertação com o objetivo de analisar e construir princípios teórico-metodológicos na Educação Física, em uma perspectiva em que a educação corporal humana não se apresente dissociada de preocupações éticas, estéticas e, principalmente, ecológicas. A intenção do autor é pensar a educação do corpo para além da sua fisiologia, uma vez que determinadas atividades exercidas pelo próprio corpo estimulam as relações dos seres humanos entre si, e destes com a natureza.

Nesse contexto, Silva (2007) aproxima a Teoria das Cinco Peles da Educação Física quando estimula reflexões sobre as relações do corpo humano com o mundo. Essas reflexões são incentivadas por meio de oficinas, promovidas para docentes da rede municipal de ensino 
de Florianópolis/SC, que objetivaram a sensibilização e construção da concepção de corpo sugerida pelo pintor Friedensreich Hundertwasser, que, por sua vez, aproxima a temática do meio ambiente.

Igualmente atentos à temática do meio ambiente, Dias e Abrão (2010) publicaram 0 artigo Projeto Cinco Peles: Educação para o Consumo Consciente e para o Lido Sustentável para com o Ambiente. Nesse artigo, produzido a partir de relatos de experiências ocorridas no projeto de educação ambiental aplicado em escolas do município de Largo/PR, os autores objetivaram questionar hábitos de consumo infantil.

A reflexão sobre consumo e cooperação foi abordada por meio da Teoria das Cinco Peles, e estimulada através de atividades corporais ligadas à ludicidade. Para os autores, as relações cooperativas foram fomentadas a partir da premissa de que brincar é uma necessidade e direito da criança, ao mesmo tempo em que é uma maneira de consumir o mundo.

Observamos, a partir dos artigos citados, uma aproximação da Educação Física a reflexões ligadas ao meio ambiente. As discussões sobre corpo a partir das Cinco Peles constituíram o ponto de partida para se repensar a relação homem-natureza. Como dito anteriormente, os significados dados ao corpo servem de base para se refletir questões que extrapolem a dimensão corporal e, no caso dos artigos supracitados, apropriarem-se do corpo para se discutir como o meio ambiente insere-se nesse contexto.

Por fim, Oliveira (2012) buscou investigar a influência do pensamento de Hundertwasser no campo educacional, bem como a formação do corpo na contemporaneidade. 0 autor, inspirado na Teoria das Cinco Peles, compreende a escola como um espaço composto por corpos, aprendizados e criatividade, que por sua vez influenciam-se entre si. Nesse sentido, a concepção de corpo é formada dentro da escola através dos aprendizados ensinados de forma criativa.

Portanto, para Oliveira (2012), pensar a educação a partir da Teoria das Cinco Peles nos faz despertar para uma educação ligada à sensibilidade. Não há uma necessidade de práticas escolares estarem ligadas estritamente a eixos temáticos, mas em saberes orientados a práticas sociais. No caso da Educação Física, esse pensamento se traduz em explorar uma concepção de corpo humano que nos auxilie a enfrentar nossos problemas sociais.

\subsection{Cinco Peles e Educação Física: as proximidades entre os autores}

A principal contribuição de Peretta (2005) está em revelar para a Educação Física que é possível compreender o corpo com múltiplas peles. Na perspectiva do autor, perceber algo inorgânico fazendo parte do nosso ser no mundo pode sugerir outras perspectivas da relação que construímos com o próprio mundo, e desta forma desenvolver um maior cuidado para nossas ações e reflexões.

Peretta (2007) amadurece a ideia, inspirada em Hundertwasser, de admitir que o corpo subjetivamente é constituído por mais de uma pele, e escreve o artigo Anatomia Altruísta. Esse artigo está em concordância com suas primeiras reflexões sobre corpo, porém concentra-se nas relações éticas e de corresponsabilidade do homem. Compreender a anatomia humana de forma altruísta é essencial para que o homem entenda-se como corresponsável por suas ações desenvolvidas em meio à sociedade. 
Influenciado por esse discurso que aproxima a Teoria das Cinco Peles e a Educação Física por meio da corresponsabilidade, Silva (2007) desenvolve a ideia de corpomundo. $O$ autor define corpomundo como a materialização de estar no mundo e se transformar com ele, diante da possibilidade de interconexão entre cultura e natureza.

Em síntese, corpomundo tem como foco as relações éticas e de corresponsabilidade, já encontradas em Peretta (2007), no entanto, concentrado em ponderações ligadas ao meio ambiente. Enquanto Peretta $(2005,2007)$ desenvolve suas reflexões sobre a corresponsabilidade de um corpo com múltiplas peles, Silva (2007) concentra-se em refletir sobre as incumbências humanas sobre a natureza. A preocupação de relacionar a responsabilidade humana ao meio ambiente foi presente nas obras de Peretta $(2005,2007)$, entretanto essa aproximação se mostrou mais evidente na dissertação de Silva (2007).

A partir das contribuições de Silva (2007), a natureza conquista espaço na Educação Física através da Teoria das Cinco Peles. Talvez essas reflexões estejam em maior concordância com a obra de Hundertwasser, visto que a maior preocupação do artista era 0 meio ambiente.

Motivados pelo discurso que aproxima preservação ambiental na Educação Física na perspectiva de Hundertwasser, Dias e Abrão (2010) realizam uma pesquisa participante para trabalhar a temática do consumismo infantil. Sendo assim, a preocupação com o ecossistema encontrada na obra de Hundertwasser, aplicada à Educação Física por Peretta $(2005,2007)$ e corroborada por Silva (2007), estende-se ao estudo de Dias e Abrão (2010). Entretanto, para os últimos, há um direcionamento da pesquisa para um determinado público, no caso, o infantil.

Abordar a temática do meio ambiente por meio de reflexões sobre consumismo foi um caminho escolhido por Dias e Abrão (2010), através de uma pesquisa-ação, para sensibilizar as crianças para o assunto. Não obstante, Silva (2007) havia optado por uma pesquisa-ação no intuito de gerar reflexões semelhantes. A diferença entre os dois estudos está no público alvo, pois Silva (2007) optou por direcionar sua pesquisa-ação aos docentes da rede municipal de Florianópolis/SC.

Oliveira (2012) também constrói suas reflexões pautado nas questões ambientais, no entanto direciona-as aos ambientes educacionais. Para o autor, a escola é um espaço de invenção e criação capaz de reeducar os hábitos da população, instituindo novos modos de viver. As atividades práticas escolares, construtoras de saberes, sugerem aprendizados orientados ao contexto social.

É importante salientar que há uma interconexão entre os autores citados anteriormente no que se refere a contribuições à Educação Física. Embora Silva (2007), Oliveira (2012), Dias e Abrão (2010) evidenciem claramente a opção por uma linha de pesquisa ligada às questões ambientais, há um elo que os une a Peretta $(2005,2007)$. Esse elo é a capacidade de compreender elementos extracorpóreos como pertencentes ao próprio corpo, buscando, nesse caminho, alternativas para despertar a Educação Física para reflexões ambientais.

\section{CONSIDERAÇÕES FINAIS}

A análise nos permitiu constatar quais os estudos relacionam a Teoria das Cinco Peles à Educação Física. Pudemos perceber que os estudos abordam relações de corresponsabilidade 
associadas a implicações sobre o meio ambiente. Sendo assim, há uma predominância em refletir sobre a quinta pele da teoria de Hundertwasser.

Na perspectiva de Hundertwasser, o meio ambiente é uma das cinco possíveis peles do ser humano. Entretanto, a teoria congrega cinco diferentes peles que se relacionam entre si. Nesse sentido, observar a teoria exclusivamente através da perspectiva do meio ambiente nos condiciona a uma visão limitada, ao passo que restringe as possíveis contribuições para a área de Educação Física.

Para Hundertwasser, as cinco peles se relacionam constantemente e por esse motivo não é possível vivenciarmos uma para posteriormente experimentarmos outras. Dessa forma, compreendê-las desmembradas umas das outras restringe nossa compreensão, assim como nos posiciona contra a própria teoria. No entanto, recomenda-se buscar aproximações com a Educação Física a partir, também, das outras quatro peles existentes.

Apropriarmo-nos de outras peles para refletir sobre corpo humano vai ao encontro de uma das tendências da Educação Física, traduzida por Soares e Madureira (2005) como aproximação da arte para se pensar sobre corpo. Portanto, construir estudos sobre as demais peles, pouco abordadas nos estudos encontrados, é uma possibilidade de alimentar essa tendência.

\section{REFERÊNCIAS}

BENTO, Teresa. Revisões sistemáticas em desporto e saúde: orientações para o planejamento, elaboração, redação e avaliação. Motricidade, Ribeira de Pena, v. 10, n. 2, p. 107-123, 2014.

DIAS, Thiago Cancelier; ABRÃO, Elisa. Projeto cinco peles: educação para o consumo consciente e para o lido sustentável para com o ambiente. Revista Espaço Acadêmico, Maringá, v. 10, n. 112, p. $51-57,2010$

HUNDERTWASSER, Friedensreich. Mouldiness: manifesto against rationalism in architecture. 1964. Disponível em: <http://www.hundertwasser.at/english/texts/philosophie.php>. Acesso em: 16 ago. 2015.

HUNDERTWASSER, Friedensreich. Hundertwasser on Hundertwasser. 1975. Disponível em: <http://www.hundertwasser.at/english/texts/philosophie.php>. Acesso em: 16 ago. 2015.

HUNDERTWASSER, Friedensreich. Window dictatorship and window right. 1990. Disponível em: <http://www.hundertwasser.at/english/texts/philosophie.php>. Acesso em: 16 ago. 2015.

GOMES, Isabelle Sena; CAMINHA, Iraquitan Oliveira. Guia para estudos de revisão sistemática: uma opção metodológica para ciências do movimento humano. Movimento, Porto Alegre, v. 20, n. 1, p. 395-411, jan./mar. 2014.

MERLEAU-PONTY, Maurice. O visível e o invisível. São Paulo: Perspectiva, 1992.

MINAYO, Maria Cecília Souza. 0 desafio do conhecimento: pesquisa qualitativa em saúde. 7. ed. São Paulo: Hucitec, 2000.

OLIVEIRA, Marcio Romeu Ribas. Hundertwassercorpoimensoeducador. Atos de Pesquisa em Educação, Blumenau, v. 7, n. 2, p. 404-422, 2012.

PERETTA, Éden Silva. Alteridades da pele, fronteiras do corpo. 2005. 154 f. Dissertação (Mestrado em Educação Física) - Universidade Federal de Santa Catarina, Florianópolis, 2005.

PERETTA, Éden Silva. Anatomia altruísta. Revista Brasileira de Ciência do Esporte, Curitiba, v. 28, n. 3, p. 125-139, 2007. 
SCHÜTZ, Gustavo Ricardo; SANT'ANA, Antônio Sérgio Santos; SANTOS, Saray Giovana. Política de periódicos nacionais em Educação Física para estudos de revisão sistemática. Revista Brasileira de Cineantropometria do Desempenho Humano, Florianópolis, v. 13, n. 4, p. 313-319, 2011.

SILVA, Fabiano Weber. Corpo e natureza: perspectivas para uma educação de corpomundo. 2007. 155 f. Dissertação (Mestrado em Educação Física) - Universidade Federal de Santa Catarina, Florianópolis, 2007.

SOARES, Carmen Lúcia; MADUREIRA, José Rafael. Educação física, linguagem e arte: possibilidades de um diálogo poético do corpo. Movimento, Porto Alegre, v. 11, n. 2, p. 75-88, maio/ ago. 2005. 